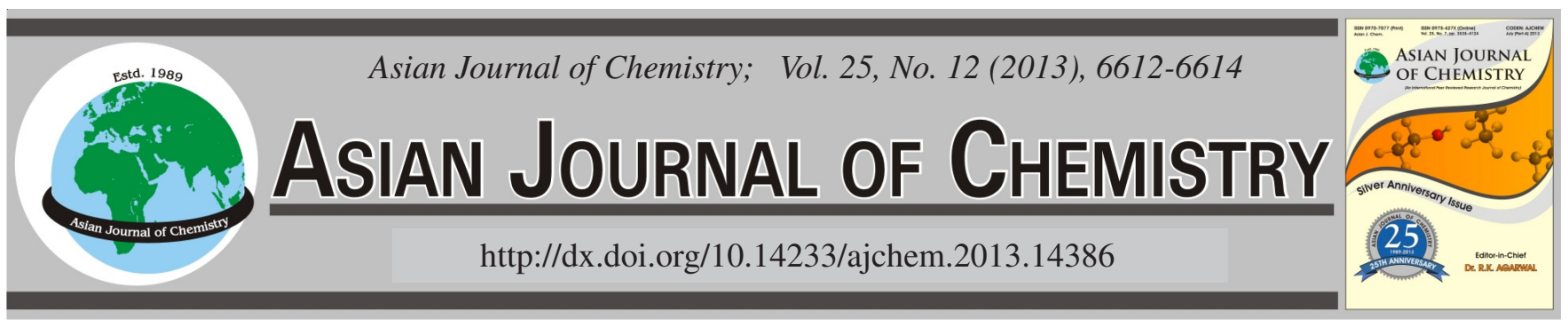

\title{
Simultaneous Determination of Loureirin A, Loureirin B and Resveratrol by HPLC in Resina Draconis Tablet
}

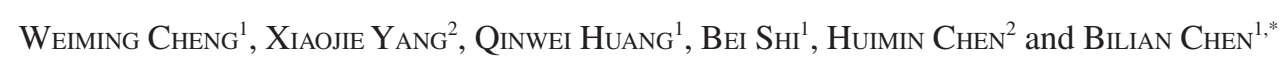

${ }^{1}$ Zhejiang Institute for Food and Drug Control, No 86, Lane 1, Jichang Road, Jianggan Dist. 310004, Hangzhou, Zhejiang Province, P.R. China ${ }^{2}$ Grade 09, College of Pharmaceutical Science of Zhejiang University of Technology, No 18, Chaowang Road, Xiacheng Dist. 310004, Hangzhou Zhejiang Province, P.R. China

*Corresponding author: Tel: +86 15858177067; E-mail: weiming_cheng@ hotmail.com

(Received: 31 July 2012;

Accepted: 22 May 2013)

AJC-13532

An HPLC method was developed for the simultaneous determination of 3 bioactive components in resina draconis tablet. The solid phase was Agilent Zorbax SB-C 18 with glacial acetic acid $(1 \rightarrow 90)$-acetonitrile as the mobile for the gradient elution. The results of the methodology all fit the analytical requests and the recoveries were 101.8, 103.2 and $104.2 \%$ for the 3 targeted components, respectively. It was the first report that figured out the method for the simultaneous determination of bioactive components with different structures in resina draconis tablet by HPLC and simple, accurate and reliable for the quality control of resina draconis tablet.

Key Words: HPLC, Resina draconis tablet, Loureirin A, Loureirin B, Resveratrol, Simultaneous determination.

\section{INTRODUCTION}

Resina draconis is a resina extracted and made from Jianye dragon blood tree, namely Dracaena cochinchinensis, which could activate blood flow and remove blood stasis, benefit vital energy, enrich the blood and promote granulation, etc..$^{1-4}$. It's mainly used for some indications like bleeding wound, traumatic injury, unhealing ulcer, etc. ${ }^{5}$. The components of resina draconis tablet are mainly favones, sterols and saponins with various biological activities and loureirin A, loureirin B and resveratrol are active ones among them ${ }^{6-10}$. To the best of our knowledge, the simultaneous determination of bioactive components with different chemical structures in resina draconis tablet had not been reported, so our purpose was to develop a method for the simultaneous determination of the above 3 components in resina draconis tablet for quality control and efficacy study in clinical use.

\section{EXPERIMENTAL}

Reference compounds and chemicals: Standards of loureirin A, loureirin B and resveratrtrol were supplied by National Institute for Food and Drug Control (Beijing, China) with the batch number of 111660-200402, 111558-200303, 111535-200502, respectively. Resina draconis tablet was purchased from Datang Hanfang Pharmaceutical Company (Yunnan, China). Acetonitrile was of HPLC grade and other reagents used were of analytical grade. Deionized water was prepared using a Millipore water purification system.
HPLC conditions: An Agilent 1200 series LC system was employed in this research, which consisted of a G1311A Quaternary Pumps, a G1322A degasser, a G1314A VWD and a G1313A Autosampler.

The separation of loureirin $\mathrm{A}$, loureirin $\mathrm{B}$ and resveratrtrol was carried out on a Agilent Zorbax SB-C ${ }_{18}(250 \mathrm{~mm} \times 4.6$ $\mathrm{mm}, 5 \mu \mathrm{m})$. The solvents used for HPLC separation of the 3 components in sample were acetonitrile (A) and glacial acetic acid $(1 \rightarrow 90)(\mathrm{B})$ at a flow rate of $1.0 \mathrm{~mL} \mathrm{~min}^{-1}$ with gradient elution (0-55 $\mathrm{min}, 20-45 \% \mathrm{~A})$ and the analysis was monitored at $260 \mathrm{~nm}$ with the column temperature of $35^{\circ} \mathrm{C}$ and the injection volume was $10 \mu \mathrm{L}$.

Preparation of sample solution: Twenty resina draconis tablets were pulverized into fine powder, passing through a $0.25 \mathrm{~mm}$ sieve, $c a$. $0.2 \mathrm{~g}$ sample was accurately weighted, then added into a $50.0 \mathrm{~mL}$ volumetric flask with $c a$. $0.1 \mathrm{~g}$ diatomaceous earth. About $35 \mathrm{~mL}$ acetonitrile and $(1 \rightarrow 90)$ glacial acetic acid (1:1) mixed solution was added for the ultrasonic batch at room temperature for $15 \mathrm{~min}$. Then cooled down and diluted to the volume. The solution was ready for chromatographic analysis after passing through a $0.45 \mu \mathrm{m}$ membrane filter.

Preparation of standard solution: Certain amounts of the 3 standard compounds were dissolved with acetonitrile into a $50.0 \mathrm{~mL}$ volumetric flask, respectively. Then measured $1.0 \mathrm{~mL}$ of loureirin A, loureirin B and resveratrol standard solution, respectively, into a $5.0 \mathrm{~mL}$ volumetric flask and diluted to the concentrations of 21.24, 24.24 and $23.24 \mu \mathrm{g} \mathrm{mL}^{-1}$. 


\section{RESULTS AND DISCUSSION}

\section{Validation of the chromatographic method}

Regression equations: Linear regression analysis for each component was performed by the external standard method. Loureirin A curves were established based on seven points with concentrations of $21.24,42.28,106.2,212.4,315.6,424.8$, $637.2 \mu \mathrm{g} \mathrm{mL}^{-1}$; seven points for loureirin B with concentrations of $24.24,48.48,121.2,242.4,363.6,484.8,727.2 \mu \mathrm{g} \mathrm{mL}^{-1}$; seven points for resveratrol with concentrations of 23.24 , $46.48,116.2,232.4,348.6,464.8,697.2 \mu \mathrm{g} \mathrm{mL}^{-1}$. The calculated results were given in Table-1. All the 3 components showed good linearities in a relatively wide concentration range.

TABLE-1

LINEAR REGRESSION EQUATION AND LINEAR RANGES

\begin{tabular}{llcc}
\hline Components & Regression equation & $\begin{array}{c}\text { Correlation } \\
\text { coefficient }\left(\mathrm{R}^{2}\right)\end{array}$ & $\begin{array}{c}\text { Linear range } \\
\left(\mu \mathrm{g} \mathrm{mL} \mathrm{mL}^{-1}\right)\end{array}$ \\
\hline Loureirin A & $\mathrm{Y}=2400.5 \mathrm{X}+17.44$ & 0.9991 & $21.24-637.2$ \\
Loureirin B & $\mathrm{Y}=2197.6 \mathrm{X}+16.50$ & 0.9991 & $24.24-727.2$ \\
Resveratrol & $\mathrm{Y}=873.5 \mathrm{X}+6.45$ & 0.9998 & $23.24-697.2$
\end{tabular}

Note: $\mathrm{X}$ denoted the concentrations and Y denoted the peak areas.

Precision: The standard mixture solution of loureirin A, loureirin B and reseveratrol was injected into HPLC six times continuously and the area of each peak was used for the calculation of precision. The results showed that relative stand deviation (RSD) of peak area of each standard was $0.3,0.3$ and $0.3 \%$, respectively.

Repeatability: Repeatability was carried out taken six samples solution with the same treatment procedure. The results showed that RSD of each peak area was $0.5,0.9$ and $0.6 \%$, respectively.

Stability: For stability test, the same sample solution was analyzed at designated time points in $48 \mathrm{~h}$. The results showed that RSDs of peak area were 1.8, 1.3 and $1.4 \%$ and found to be stable for the experiment.

Recovery test: The sample with determined targeted contents was spiked with certain amounts of the 3 standards.
Then the spiked sample was processed in accordance with the established method for the HPLC detection. The average recoveries for loureirin A, loureirin B and resveratrol determined were 101.8-104.2\% (Table-2).

Application of the HPLC method for quantitation studies: $10 \mu \mathrm{L}$ sample solution was injected into the instrument. The representative HPLC chromatograms were shown in Fig. 1, respectively. Peaks in the obtained chromatograms were identified by comparing the retention time and on-line UV spectra with those of the standards.

The contents of the 3 components in resina draconis tablet were calculated and shown in Table- 3 .

\begin{tabular}{cccc} 
TABLE-3 \\
CONTENTS OF LOUREIRIN A, LOUREIRIN B AND \\
\multicolumn{4}{c}{ RESVERATROL IN RESINA DRACONIS TABLET } \\
\hline $\begin{array}{c}\text { Batch } \\
\text { number }\end{array}$ & $\begin{array}{c}\text { Loureirin A } \\
\left(\mathrm{mg} \mathrm{g}^{-1}\right)\end{array}$ & $\begin{array}{c}\text { Loureirin B } \\
\left(\mathrm{mg} \mathrm{g}^{-1}\right)\end{array}$ & $\begin{array}{c}\text { Resveratrol } \\
\left(\mathrm{mg} \mathrm{g}^{-1}\right)\end{array}$ \\
\hline 20120305 & 3.60 & 5.34 & 5.81 \\
20120401 & 3.46 & 5.21 & 5.55 \\
20120604 & 3.53 & 5.26 & 5.61 \\
\hline
\end{tabular}

Optimization of HPLC separation conditions: In order to get a separation with better resolution of targeted components with shorter analytical time, we compared with three different column temperature: 20,35 and $40^{\circ} \mathrm{C}$, then we found that the higher temperature, the shorter retention time with almost the same resolution, so we chosen $35^{\circ} \mathrm{C}$ finally for protecting the lifespan of the column.

Besides, reflux extraction and ultrasonic extraction were investigated in the experiments. Considering the advantages of high efficiency and easy operation, we chosen ultrasonic extraction as the way to prepare sample solution. In the meantime, we compared the efficiency of methanol with acetonitrileglacial acetic acid $(1 \rightarrow 90)(1: 1)$ which were used to for ultrasound, it was shown that the latter was slightly better. We also tried different ultrasonic time: 10, 15, 25 and $30 \mathrm{~min}$. Finally, taken the determination of targeted components into consideration, ultrasonic extraction $15 \mathrm{~min}$ with acetonitrile-glacial acetic acid $(1 \rightarrow 90)(1: 1)$ was better.

\begin{tabular}{|c|c|c|c|c|c|c|}
\hline \multicolumn{7}{|c|}{$\begin{array}{c}\text { TABLE-2 } \\
\text { RECOVERIES OF THE } 3 \text { COMPONENT }(n=6)\end{array}$} \\
\hline Component & Contents in materials (mg) & Added (mg) & Found (mg) & Recovery (\%) & Mean $(\%)$ & $\operatorname{RSD}(\%)$ \\
\hline \multirow{5}{*}{ Loureirin A } & 0.2092 & 0.1986 & 0.4115 & 101.85 & \multirow{5}{*}{101.8} & \multirow{5}{*}{1.8} \\
\hline & 0.2028 & 0.2102 & 0.4216 & 104.10 & & \\
\hline & 0.2165 & 0.1923 & 0.4142 & 102.82 & & \\
\hline & 0.2133 & 0.1994 & 0.4123 & 99.78 & & \\
\hline & 0.2137 & 0.1923 & 0.4050 & 99.46 & & \\
\hline \multirow{6}{*}{ Loureirin B } & 0.3104 & 0.3525 & 0.6753 & 103.53 & \multirow{6}{*}{103.2} & \multirow{6}{*}{0.6} \\
\hline & 0.3008 & 0.3586 & 0.6693 & 102.76 & & \\
\hline & 0.3221 & 0.3385 & 0.6667 & 102.10 & & \\
\hline & 0.3164 & 0.3447 & 0.6719 & 103.12 & & \\
\hline & 0.3170 & 0.3397 & 0.6700 & 103.90 & & \\
\hline & 0.3182 & 0.3532 & 0.6837 & 103.48 & & \\
\hline \multirow{5}{*}{ Resveratrol } & 0.3377 & 0.3802 & 0.7352 & 104.56 & \multirow{5}{*}{104.2} & \multirow{5}{*}{0.8} \\
\hline & 0.3494 & 0.3621 & 0.7219 & 102.88 & & \\
\hline & 0.3443 & 0.3683 & 0.7282 & 104.24 & & \\
\hline & 0.3449 & 0.3685 & 0.7293 & 104.30 & & \\
\hline & 0.3462 & 0.3789 & 0.7453 & 105.33 & & \\
\hline
\end{tabular}



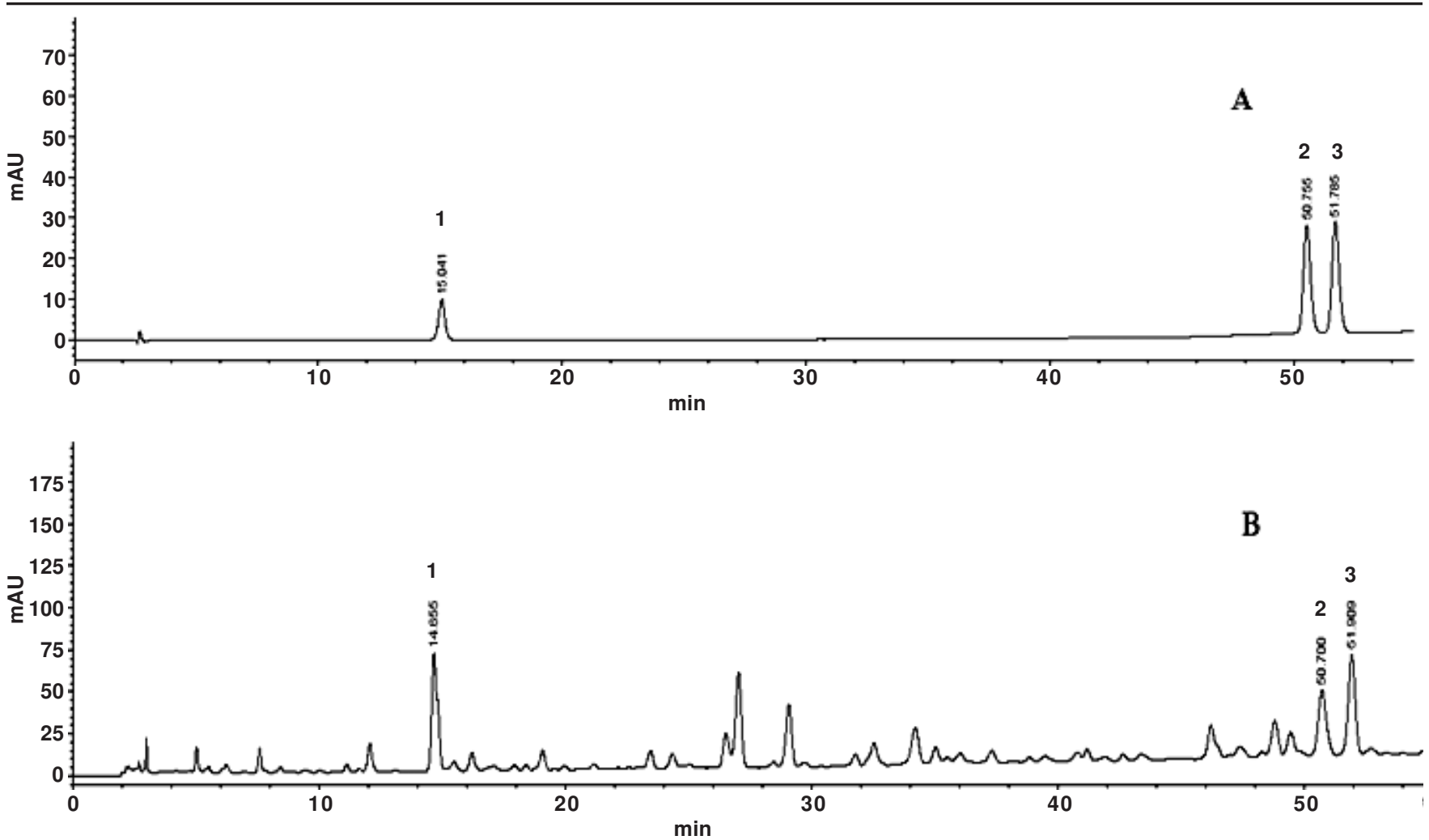

Fig. 1. Typical HPLC chromatograms of standard solution (A) and sample solution (B) 1. loureirin A; 2. loureirin B; 3. resveratrol

Three chromatographic columns were compared in the experiment: Agilent Zorbax SB-C 18 (250 $\mathrm{mm} \times 4.6 \mathrm{~mm}, 5$ $\mu \mathrm{m})$, Kromasil $100-5 \mathrm{C}_{18}(250 \mathrm{~mm} \times 4.6 \mathrm{~mm}, 5 \mu \mathrm{m})$ and Extend- $\mathrm{C}_{18}(250 \mathrm{~mm} \times 4.6 \mathrm{~mm}, 5 \mu \mathrm{m})$, according to the effect of separation, Agilent Zorbax SB-C 18 (250 mm $\times 4.6 \mathrm{~mm}, 5 \mu \mathrm{m})$ was used for the further research of the methodology.

\section{Conclusion}

In this study, 3 active components were quantitatively determined in resina draconis tablet. To the best of our knowledge, it was the first article which simultaneously determined loureirin A, loureirin B and resveratrol not only quantitatively but also qualitatively. On the whole, this developed method was simple, accurate for the determination of loureirin A, loureirin B and resveratrol simultaneously and reliable for the quality control and further efficacy study of resina draconis tablet in clinic.

\section{REFERENCES}

1. S.L. Huang, X.F. Chen, X.J. Chen and H. Liu, J. Chin. Med. Mater., 17, 37 (1994).

2. J.L. Xiang, R. Chen and L.H. Zhang, West China J. Pharm. Sci., 15, 430 (2000).

3. J.L. Xiang, L.H. Zhang, R. Chen and X.H. Zhang, Li Shi Zhen Med. Mater. Med. Res., 12, 110 (2001).

4. D.L. Chen, Q.Y. Gao, W.M. Shi, Z. Xu, Y.L. Pu and L.L. Shen, Shanghai Med. J., 23, 145 (2000).

5. D.X. Wen, Chin. Trad. Herbal Drugs, 11, 1053 (2001).

6. J.X. Chen, B.H. Qiu, L.M. Pan and L. Bian, Chin. Med. J. Res. Prac., 25, $81(2011)$

7. T.B. Zhang, J.C. Lv, K.L. Yong, L.R. Xu and X. Cheng, Nat. Prod. Res. Dev., 20, 695 (2008).

8. S.T. Wang, S. Chen, M. Guo and X.M. Liu, Brain Res., 12, 34 (2008).

9. Y.Q. Hu, P.F. Tu, R.Y. Li, M.X. Zhao, F.C. Luo and J.X. Fang, Chin. Trad. Herbal Drugs, 32, 104 (2001).

10. Z.P. Liu, B. Yu, Q.L Guo, H. Huang, C.J. Pan, Y.R. Zhao and X.Q. Gao, J. Hygiene Res., 31, 188 (2002). 